ANALYSIS 50 (1990): 19-24

\title{
ARE SALMON'S ‘GUISES' DISGUISED FREGEAN SENSES?
}

\author{
By João Branquinho
}

I

N a review of Frege's Puzzle ${ }^{1}$, Graeme Forbes makes the claim that Salmon's account of belief might be seen, under certain conditions, as a mere notational variant of a neoFregean theory; and thus that such an account might be reduced to a neo-Fregean one simply by rewriting it in terms of Fregean terminology. With a view to supporting his claim, Forbes offers an outline of an account of belief which, according to him, would satisfy the following conditions: (i) it could be directly obtained from Salmon's own analysis by means of a certain set of substitutions, which presumably would not affect the essential features of Salmon's view; (ii) it could naturally be described as Fregean, in the sense that it would preserve, (at least) the spirit of Frege's doctrines, especially his fundamental intuitions about belief. Of course, the upshot of Forbes's argument is that Salmon's theory would not, at bottom, constitute a genuine alternative to a Fregean semantics for belief ascriptions.

In this paper I shall argue to the effect that Forbes's claim is not in general sound. It seems to me that the sort of indirect argument used by Forbes - that of trying to undermine Salmon's theory by showing that it is just a version of a neo-Fregean account - does not provide someone working within a Fregean framework with an adequate strategy to counter Salmon's neo-Russellian views. It would perhaps be better to concentrate a Fregean attack on certain apparently dubious and highly controversial theses and results which are constitutive of Salmon's view, e.g. the counterintuitive character of a substantial set of consequences which follow from his theory of belief, as well as the associated revisionist stand he is forced to take towards our current patterns of speaking about belief.

Forbes is surely right when he says that Salmon's account implies the possibility of ascribing inconsistent beliefs to some agent. Suppose that our believer, on the basis of his visual encounters with Venus at dawn, thinks that Phosphorus is a star, and that, on the basis of his encounters with Venus at dusk, he thinks that Hesperus is not a star, but a planet. Let us represent Salmon's account by the formula

(S) A believes that $p$ iff (Ex)[A grasps $p$ by means of $x \& \operatorname{BEL}(A, p, x)$ ]

where ' $\mathrm{A}$ ' and ' $\mathrm{p}$ ' stand for a believer and a proposition, respectively, and ' $\mathrm{x}$ ' ranges over ways by means of which A is acquainted with $p$ (guises). Using Salmon's characterization of a guise as a binary function $\mathrm{f}(\mathrm{A}$, ' $\mathrm{S}$ '), mapping a believer $\mathrm{A}$ and a sentence ' $\mathrm{S}$ ' onto the way A would take the proposition encoded in 'S' were this proposition presented to him through 'S', the following hold (with respect to our story):

(1) BEL[A, that Hesperus is a star, $\mathrm{f}(\mathrm{A}$, 'Phosphorus is a star')]

(2) BEL[A, that Hesperus is not a star, $\mathrm{f}(\mathrm{A}$, ,Hesperus is not a star')].

By (S) one obtains from (1) and (2), respectively, the following as true:

(3) A believes that Hesperus is a star

(4) A believes that Hesperus is not a star.

Hence Salmon's theory allows us to attribute contradictory beliefs to A, though it does not

\footnotetext{
${ }^{1}$ Nathan Salmon, Frege's Puzzle (Cambridge MA: MIT Press, 1983): reviewed by Graeme Forbes, Philosophical Review 96 (1987) 455-8.
} 
allow us to describe him as an illogical or irrational believer. whereas A believes the proposition that Hesperus is a star under the guise $\mathrm{f}(\mathrm{A}$, 'Phosphorus is a star'), he believes the contradictory of that proposition under the guise $\mathrm{f}(\mathrm{A}$, 'Hesperus is not a star'), and the sentence 'Hesperus is not a star' is obviously not the negation of the sentence 'Phosphorus is a star'. Of course, these observations do not render Salmon's analysis any less counterintuitive for it has in any case the consequence that A believes that Hesperus is a star tout court and also believes that Hesperus is not a star tout court, but they somehow mitigate the implausibility of such a consequence.

Forbes's neo-Fregean reconstruction of Salmon's theory consists in subjecting (S) to the following substitutions: (i) on the righ-thand side, replace the ternary predicate 'A grasps $p$ by means of $\mathrm{x}$ ' by 'A thinks of $\mathrm{p}$ by means of $\mathrm{x}$ ', where ' $\mathrm{A}$ ' stands for a believer and ' $\mathrm{p}$ ' and ' $\mathrm{x}$ ' range over states of affairs and propositions, respectively; (ii) still on the right-hand side, replace 'BEL(A,p,x)' by the conjunction ' $\mathrm{B}(\mathrm{Ax}) \& \mathrm{p}=\operatorname{Ref}(\mathrm{x})$ ', where 'A', 'p', ' $\mathrm{x}$ ' are as above, 'B' stands for the belief-relation, and 'Ref' stands for the Reference function, which in this case assigns to each proposition $\mathrm{x}$ some state of affairs as its referent; (iii) substitute " $p$ is believed by A to obtain' for the left-hand side. The result would be the formula:

$(F) p$ is believed by $A$ to obtain iff $(E x)[A$ thinks of $p$ by means of $x \& B(A, x) \& p=\operatorname{Ref}(x)]$.

Thus, Forbes's states of affairs replace Salmon's propositions and Forbes's propositions replace Salmon's guises. The underlying idea is that states of affairs are the referents of sentences, or (to be precise) the referents of the propositions expressed by these sentences. It is implicitly assumed that the relation between a proposition $\mathrm{x}$ and a certain state of affairs $p$ is the relation which obtains between Fregean sense (the proposition expressed by some sentence ' $S$ ') and reference (the state of affairs referred to by ' $S$ '); and this relation is to the effect that sense determines reference, so that we can say that a sentence ' $\mathrm{S}$ ' refers to a state of affairs $\mathrm{p}$ only in a derivative way; primarily, it is the proposition $\mathrm{x}$ expressed by ' $\mathrm{S}$ ' which determines $\mathrm{p}$ as its referent. Since his states of affairs coincide with Salmon's propositions - they are indeed conceived as displaying precisely the same composition as Russellian propositions, viz. an object coupled with a property - Forbes contends that Salmon's concept of a guise plays in (S) exactly the same role as the concept of a Fregean sense in (F). Given that a Russellian proposition $\mathrm{p}$ is an entity structured in the way described above, every guise under which one can take $\mathrm{p}$ is bound to have as constituents a manner of grasping some object a and a manner of grasping some property F. But such manners of grasping are no other than the Fregean senses which together make up the proposition $\alpha^{\wedge} \beta$, where ' $\alpha$ ' and ' $\beta$ ' stand for modes of presentation of a and F, respectively (I use ' $\wedge$ ' for concatenation of senses). Therefore, just as in Forbes's analysis (F) a (Fregean) proposition $\mathrm{x}$ is a mode of presentation of some state of affairs $\mathrm{p}$, so in Salmon's analysis (S) a guise $\mathrm{x}$ could be viewed as being, in essence, a mode of presentation of some (Russellian) proposition (=state of affairs)) p. (I assume that we are only dealing with singular propositions, i.e., those which may be expressed by sentences constructed out of simple unary predicates and simple singular terms.)

Although I think that the above considerations show that there must be some sense in which Salmon's account could be seen as invoking the same kind of conceptual apparatus as the neoFregean theory, I shall argue that Forbes's notational variation' claim cannot be accepted; and if I am right, Salmon's guises cannot be assimilated, at least on that basis, to Fregean senses.

If Salmon's (S) is to be regarded as a notational variant of its neo-Fregean counterpart $(\mathrm{F})$, then $(\mathrm{F})$ itself is bound to have the same consequences as $(\mathrm{S})$; in particular, $(\mathrm{F})$ is bound to yield exactly the same verdicts on the truth-values of given belief ascriptions. But either this is not the case, and then Forbes is wrong in claiming that Salmon's account is a notational variant of $(\mathrm{F})$; or it is the case, but then $(\mathrm{F})$ would at once disqualify itself as Fregean (for 
obvious reasons). I shall now try to show that the first branch of this disjunction holds.

Having in mind A's story one could reason as follows. Let ' $x$ ' be |Phosphorus is a star|. Then one would clearly obtain the following (for convenience, I abbreviate the state of affairs that p' to ' $/ \mathrm{p} /$ '): $^{2}$

(5) $(\mathrm{Ex})[\mathrm{A}$ thinks of /Hesperus is a star/ by means of $\mathrm{x} \& \mathrm{~B}(\mathrm{~A}, \mathrm{x}) \& /$ Hesperus is a $\mathrm{star} /=$ $\operatorname{Ref}(\mathrm{x})]$.

And, by $(\mathrm{F})$, we come to the conclusion that

(6) The state of affairs that Hesperus is a star is believed by A to obtain.

On the other hand, by letting ' $x$ ' be $\mid$ Hesperus is not a start $\mid$ and applying $(F)$, one would also derive the following

(7) The state of affairs that Hesperus is not a star is believed by A to obtain.

So the conjunction of (6) and (7) implies at least that A believes of inconsistent states of affairs that they both obtain. But is there any sense in which this could amount to ascribing contradictory beliefs to A?

In order to answer this question we have to determine whether or not (6) and (7) might receive, respectively, the readings:

(8) A believes that the state of affairs that Hesperus is a star obtains

(9) A believes that the state of affairs that Hesperus is not a star obtains.

If so, I would argue on Fregean grounds that (8) and (9), and hence (6) and (7), are respectively the same as (3) and (4), in which case (F) would indeed entail the possibility of our ascribing inconsistent beliefs to A. Taking (8) as an example, the occurrence of the singular term 'the state of affairs that Hesperus is a star' there must have as its reference, not its customary reference (viz. a certain state of affairs, e.g. the reference of the sentence 'Phosphorous is a star'), but that which is its customary sense; and, using Forbes's assumptions, this sense is a concept of that state of affairs, viz. the Fregean proposition |Hesperus is a star | (which might be expressed by the sentence 'Hesperus is a star occuring by itself). ${ }^{2}$ Thus, the Fregean regimentation for (8) is

(10) $\mathrm{B}[\mathrm{A}, \mid$ Hesperus is a star $|\wedge|$ obtains $\mid]$,

which may be presumably abbreviated to

(11) B[A, |Hesperus is a star |],

which in turn is the Fregean regimentation for (3). (A similar argument could be applied to

\footnotetext{
${ }^{2}$ Actually it could be that the description 'the state of affairs that p' might express a slightly different (perhaps more intimate) way of thinking of a state of affairs than that which is expressed by the sentence 'p'; but I ignore the complication here.
} 
(9).)

However, there is a strong reason to think that Forbes would not allow (6) and (7) to have, respectively, the readings (8) and (9). The reason is that e.g. (6) would rather receive (in Forbes's terminology) the 'external form' reading

$\left(6^{*}\right)$ The state of affairs that Hesperus is a star is something A believes to obtain

where the occurrence of the singular term 'the state of affairs that Hesperus is a star' is an external occurrence and has as its reference the customary reference of the term (the state of affairs itself, being thus open to replacement salva veritate by any coreferential singular term. By contrast, in (8) the occurrence of the same term is internal and (8) is itself an internal form. Now the logical relations which are seen to hold between external forms and the corresponding internal forms is that the former ascriptions can always be inferred from the latter ones, while the converse deduction is not valid in Forbes's theory; that is, whereas a belief-ascription of the general form

$\left.{ }^{*}\right)$ a is something A believes to be $\mathrm{F}$

is entailed by a belief-ascription of the form

${ }^{(* *)}$ A believes that a is $\mathrm{F}$,

the converse inference is not allowed. It follows that $(6)$, read as $\left(6^{*}\right)$ which has the form $\left(^{*}\right)$, does not entail (8), which has the form (**). Thus, (6) cannot have the reading (8), and the same would apply to (7) and (9).

Our general conclusion is that, under such circumstances, Forbes's analysis $(\mathrm{F})$ does not yield the same consequences, concerning the truth-values of belief-ascription such as (3) and (4), as Salmon's analysis (F); for instance, whereas (S) implies that (3) is true (in our story), (F) would entail the falsity of (3). This is sufficient to establish the result that, pace Forbes, Salmon's theory is not a notational variant of a neo-Fregean account (as represented in (F)). Nevertheless, and independently of translation considerations, Forbes's reconstruction has the merit of enabling us to see Salmon's theory, from a Fregean point of view, as misinterpreting belief-ascriptions by treating states of affairs as the objects of belief. $^{3}$

New College,

Oxford OX $13 B N$

\footnotetext{
${ }^{3}$ I am very grateful to Timothy Williamson and to Graeme Forbes for their helpful remarks. I also thank the anonymous referee. This paper was written when I held a Calouste Gulbenkian Foundation Fellowship.
} 